\title{
Stepping Out: Dare to Step Forward, Step Back, or Just Stand Still and Breathe
}

\author{
MARY SUE WAISMAN, MSc, PDt, FDC, Nutrition Consultant, Fall River, NS
}

\begin{abstract}
It is important to step out and make a difference. We have one of the most unique and diverse professions that allows for diversity in thought and practice, permitting each of us to grow in our unique niches and make significant contributions. I was frightened to 'step out' to go to culinary school at the age of 46, but it changed forever the way I look at my profession and I have since experienced the most enjoyable and innovative career. There are also times when it is important to 'step back' to relish the roots of our profession; to help bring food back into nutrition; to translate all of our wonderful science into a language of food that Canadians understand. We all need to take time to 'just stand still and breathe': to celebrate our accomplishments, reflect on our actions, ensure we are heading toward our vision, keep the profession vibrant and relevant, and cherish one another.
\end{abstract}

(Can J Diet Pract Res. 2012;73:147-150)

(DOI: 10.3148/73.3.2012.147)

\section{RÉSUMÉ}

Il est important de prendre du recul et de faire une différence. Notre profession est l'une des plus uniques et diversifiées. Elle est caractérisée par une pluralité de pensées et de pratiques qui nous permet d'évoluer dans nos créneaux respectifs et d'avoir un impact significatif. À l'âge de 46 ans, je m'apprêtais à « prendre du recul » en prenant la direction de l'école de cuisine. Or, cette expérience a changé à jamais ma façon de voir ma profession, et depuis, je n'ai jamais envisagé de quitter cette carrière si inspirante et novatrice. Il y a aussi des moments où il est important de « prendre du recul » pour savourer les racines de notre profession; pour contribuer à remettre les aliments au cœur de la nutrition; pour traduire cette magnifique science des aliments en une langue que les Canadiennes et Canadiens comprennent. Nous devons tous prendre le temps de « simplement nous arrêter et de respirer » : de célébrer nos réalisations, de réfléchir à nos actions, de nous assurer qu'elles sont en harmonie avec notre vision, de faire en sorte que notre profession demeure dynamique et pertinente, et de nous aimer les uns les autres.

(Rev can prat rech diétét. 2012;73:147-150)

(DOI: 10.3148/73.3.2012.147)

\section{INTRODUCTION}

I believe I was chosen as your 2012 Ryley-Jeffs Memorial Award winner not just because of my willingness to step out as a pioneer, but perhaps more so for having the courage, vision and foresight to step back, to just stand still and breathe and not lose those methods, knowledge and activities that are at the root of our profession.

\section{Stepping out}

Stepping out requires courage, which often requires you to do something that frightens you. I was frightened to take the initiative to venture into the media world in the 1980s to try and 'show' consumers what all the nutrition science looked like in the 'tool of my trade' - the wonderful language of food. I was passionate about this, as I saw our nutrition messages causing clutter and confusion for the consumer and wanted this to change. I needed to preserve my integrity as a dietitian and be an effective translator of the complex science of nutrition, so I overcame my fears and ventured out to write, speak on radio and secure regular TV spots to show people how to eat - because people eat food, not nutrients.
I was even more frightened to 'step out' and go to culinary school at the age of 46, but it was time to live my dream and passion and unite the culinary world with dietetics. I felt such relief to move from practising mainstream dietetics to the two most enjoyable years of my life learning in the kitchen alongside world class chefs. In culinary school, I filled my head with everything I could about food and cooking! I folded dough to make Danish pastry, deboned quail, spun sugar to make croquembouche, brunoised carrots, and cut hundreds of pounds of onions. Had these people never heard of a food processor? No way! We had to cut and cut until we could cut the onion properly. I was proud to graduate as Valedictorian, with many awards and scholarships. Was I nuts to have made this decision? Probably many people thought so. Did I have the time of my life? Absolutely! Did it change forever the way I looked at my profession? Definitely. It was simply life-altering and I never looked back, only forward to 'stepping out' into a most enjoyable and innovative career. 


\section{Stepping back}

Stepping out also required me to step back, and this is perhaps where I believe my receipt of this award really matters. In my view, progress must be balanced against preserving those parts of our past that define us. That has been my goal in stepping back to our roots in food and home economics. Only by knowing where you've come from can you develop your authentic style and figure out what's important for today and tomorrow. We were founded and grounded in the halls of Home Economics, but as with any discipline, progress was our destiny, leaving behind what some viewed as too 'Becky Home-ecky' world of Home Economics. But had we strayed too far and forgotten about food?

So, I stepped right back to the founding roots of my profession - getting right back to the basics of cooking, and being proud to do it. Carrying a side of beef over my shoulder to the band saw connected me to my food. Now I got it - I saw the muscle fibres. I now knew why people told dietitians they were a bit nutty to take lean cuts, roast them and enjoy the shoe leather! If we want people to eat better, we have to do a stellar job of telling the science while showing them what it looks like with real food: how to make that lean cut truly tender; how to use ingredients to add flavour; how to work with the food they love - not just the food we want them to love!

One incredibly important concept that came through loud and clear in culinary school was that food is meant to provide pleasure to people. As I looked around at many of our nutrition messages, we were often taking food away or altering it in ways that made it tasteless and uninteresting and this really worried me. Were we taking away the pleasure of eating? Had we gone too far and ruined this fundamental right for people to feed themselves with their customary and traditional foods? I was getting a bit concerned that as a profession, we had contributed to making people feel miserable and guilty about their food choices and eating habits.

I surely didn't go into this profession to make people feel badly and I doubt you did either. If it's turkey with crispy skin and mashed potatoes with real gravy made from drippings at Thanksgiving once a year, why not? Does one day of crispy skin and gravy with a wee bit of wine truly destine you to a quadruple bypass? I think not. Or does it give you time and space to sit with your family at the table and savour both food and conversation? Does it give opportunity to learn how to make grandma's stuffing from the old country and learn why you always use the turkey neck, but not the heart when making gravy?

Today, such traditions are at risk of being forever lost if we don't make the time to preserve them. Get grandma to write down the stuffing recipe in her own handwriting as a keepsake for generations to come; better yet, stand by her side with your siblings and children and make it together so no 'secret ingredient' is left out!

\section{Ensuring food remains central to our profession}

Do all dietitians need to go to culinary school? Of course not, but just look at what's happening to ensure that food remains central to our work:
- Culinary Clubs are opening in dietitian's homes

- New cooking programs for children are popping up

- Dietitians are helping Canadians to rekindle the pleasures of cooking and family meal gatherings and showing them that dietitians are delicious food people and not the food police!

- Research is studying dietetics students' perceptions about the role of cooking and food in modern dietetics.

I beam with pride about the cookbook contributions I've made to our profession. Simply Great Food from 2007 has sold thousands of copies and continues to grace bookcases across Canada (1). COOK! was put together in record time in 2010 (2). For nine months, 16 hours a day, I selected from hundreds of recipe submissions from dietitians and consumers across Canada, wrote daily grocery lists, shopped once or twice daily, tested eight to 10 recipes per day, washed dishes endlessly, weighed ingredients, disposed of thousands of pounds of compost, fed neighbourhood children to test 'kid-friendliness' of recipes, and fed university students to test if they would ever cook this.

And I tested and tasted to ensure the food was not just good, but truly delicious and full of flavour and pleasure! I had to prove to people that healthy cooking is affordable, tastes amazing and is within their reach in their home kitchen!

The recipes I received reflected how Canadians were cooking. Bits and pieces and ground meat and fowl were plentiful, but whole cuts of meat were scarce. Except for a few innovative recipes for roast chicken and duck and lots of pork tenderloin, there were no recipes for roast beef or pork. Why? My personal view is that folks may simply have been intimidated or not know how to roast properly, when in fact it's so simple and is an ideal product to cook once and eat two or three times in following days. We enjoyed lots of delicious salmon, but healthy fats live in other fish too. What about some more mackerel, herring, sardines or trout? It was so refreshing to see lots of interesting ways with pulses, from savoury to sweet - congratulations Canada for using a vast array of these wonderful, bountiful ingredients from the heartland of Canada.

My biggest pet peeve in all the recipe testing was batch after batch of what I affectionately came to call 'brown blobs' - the results of people fiddling with a cookie recipe, removing most of the fat, adding flax or other options and ending up with something that in no way resembled a cookie. I'll give folks ' $\mathrm{A}$ ' for effort, because trying to mimic the texture of a rich cookie in the home kitchen is a tall order. The food science behind it is complex. So, if you want to tamper with a cookie, realize the end product may not be the cookie of your dreams - it will be some version of a 'brown blob'. It will not look or taste 'bad', but it will be different, and if that's the taste/texture you prefer, then carry on.

In my opinion, I'd rather leave the cookie alone; if you want a crispy chocolate chip cookie, make your favourite version, grab a glass of ice cold milk, eat ONE, and enjoy every bite guilt-free!!

To reiterate, is it necessary for each of us to attend culinary school? Absolutely not. Is it necessary for each of us to have a working knowledge of food? In my opinion, absolutely! There are wonderful innovations cropping up in universities across 
the country to help students gain a working knowledge of food and cooking:

- Unique food courses profiling foods from all ethnic backgrounds

- Cooking demos at farmers' markets

- Pulse cooking competitions

- Videos of cooking demonstrations

It occurred to me this past spring that if I wanted my messages spread as widely as possible about the importance of family meals, food and cooking in our profession, flavour and pleasure, and that it's ok to sometimes to cook a recipe without first looking at the detailed nutrient analysis, a great place to start was with our own Food and Nutrition students.

So, I donated a copy of my book Flavour First-delicious food to bring the family back to the table to every student enrolled in a Maritime Food and Nutrition program (3). Some of the comments on this offering are instructive:

- "This is my very first cookbook!"

- "How can we as dietitians tell people what and how to eat and cook if we do not know how to do so ourselves?"

- "The genuine passion you have for making food about the shared experience of preparing and enjoying together at meal time, and the positive impact that practice has on our lives, is something that we all need to be reminded of."

- "I made the pulled pork. My 16-year-old little brother said,

'This is one of the best meals I have ever had. This is better than the pulled pork from the man who sells it at the farmers' market!"”

- And one final very telling final comment: "the more I cook; the better I eat!!”

There have also been plenty of food-focused continuing education events in our Canadian dietetic community in the last while, including:

- A focus on authentic Ukrainian cooking

- Homemade Healthy - a Culinary Workshop incorporating locally grown ingredients

- In Halifax, I organized a day-long cooking event where chefs from our local culinary school and dietitians worked tirelessly to create a delectable menu of ceviche, vichyssoise with Stilton, maple salmon, seafood risotto, and chocolate crème brûlée, all complete with wine pairings. We dined in moderation like queens and learned tremendous cooking techniques.

- And perhaps most notably, at recent Dietitians of Canada

(DC) conferences, there were fabulous food tours in Vancouver and Montreal and hands-on cooking workshops in kitchens in Winnipeg, Charlottetown, and Montreal.

Now I realize and respect there are some of you who may have little use for this foodie message and fear the pendulum may swing too far back into the world of Home Economics. However, I have great confidence that with careful thought we're ready for balance again in the profession; with fulsome respect for our Home Ec roots while continuing to forge new worlds in our extraordinary and ever-widening science base.

Let's continue to do important research in dietetics, but as the research unfolds, recognize when it's time to 'step out' and forge new worlds. And as your exciting research results roll in, just 'step back' for a moment and ask, what are the implications of this research on how people feed themselves?

\section{Importance of food and agriculture}

One critical food-focused area of our profession that frankly frightens me because so few of us seem to be immersed in this important world, is food and agriculture. Stand still for just a moment and reflect. As dietitians, we work to ensure the nutritional well-being of people all around the world, but if you're asked, what role will dietitians play in feeding nine billion people by 2050, what do you say? Are you prepared to have an informed discussion on the topic? What are the key issues?

Are you prepared to engage in constructive dialogue with your peers and other food and agricultural experts on how to feed the world? We simply just cannot stand by and assume that someone else will look after that. It's our duty to stay informed, to contribute, and to keep our profession relevant on these global issues. Get involved on the international stage and agenda. As many of you travel off to the International Congress of Dietetics this year in Australia or to other international conferences, seek out opportunity to engage in this very critical dialogue.

Let's also remind ourselves about Vision 2020 (4). I was fortunate to be your Board Chair as this vision was being created and rolled out in 2007. Five years later, we all need to ask ourselves - how are we doing? The four parts of the vision are:

1. Leaders in promoting health and wellness

2. Work in diverse roles in new settings and up to our full potential

3. Professionalism: what is the right thing to do vs. what can be done

4. Innovative education that is accessible, flexible, inclusive and innovative

The year 2020 is only eight short years away. Will we fulfill our vision? And don't look to your neighbour or to DC staff to make it happen: each and every one of us is DC and it's our duty to fulfil the vision of the profession to keep it relevant and strong. If we don't lead our own way, someone else will do it for us... or, perhaps a worse fate, we will be viewed as irrelevant and ineffective.

My belief in keeping a food focus in our profession may require us to step back and truly treasure our Home Ec roots. If you've lost your food knowledge, find a way to get it back and be proud to say you are a food expert, not ashamed that you know about food and know how to cook. Remember: people eat food, not nutrients.

\section{Power of the family meal}

Let's stand still again for a moment and just think and breathe. Long before there was 'evidence' on the value of the family meal, as I was growing up in the '50s and ' 60 s, it was just 'the way it was' and made good common sense to eat with your family at the table every day. It was practical, economical, delicious and fun. Without knowing it at the time, it was one of the most powerful influences in my life. It was where family gathered to share the events of the day, to capture life's wisdom from parents, grandparents 
and siblings, to share joy and heartache from the day's events, and to enjoy true conversation face to face, not Facebook to Facebook.

What of the family meal today - is it on the brink of extinction? Here's a powerful story about teens and family meals that was the true inspiration for my book Flavour First (3). When my daughter was in grades 11 and 12, back in 2005 and 2006, some Friday night observations gave me pause for concern. Several of her friends would often gather at our home after school on Fridays. As 6 o'clock rolled around, nobody left to go home and I thought, "Don't these kids need to get home for supper?" Apparently not!

So, I simply did what my mother would have done and started to cook - nothing terribly elaborate, a pot of spaghetti and a salad or chili and buns. And I invited them all to sit together at the dining room table. What happened next was magical - real conversation flowed freely on all sorts of topics and when the time was right, they did the dishes, thanked me for the meal and came back week after week. Was I going to say no to this new ritual? Not on your life! This carried on for months and was so telling to me about the power of the family meal, and about cooking and eating together.

With our frantic pace of life that we somehow tolerate for unknown reasons, we are convincing ourselves that cooking a meal for our family takes too long, is too costly, tasteless and simply a 'chore'. It terrifies me that the family meal at the dinner table is on the brink of extinction. But I implore you - don't let this happen. We must STEP OUT and defend the family meal.

The power of a family meal is real and the scientific evidence is compelling (5). If as dietitians we long for children and adolescents to eat better, then keep the family meal. If we as a society long for our teens to avoid smoking and the use of other drugs, then keep the family meal. If we want our children to come to us to solve problems, keep the family meal.

I'm a huge believer in food traditions and the passing down of food culture. It tells the world where we came from and who we are and connects our children to their past. It could be birthday rituals or grandmothers teaching a three-year-old to make pie crust or great-aunts teaching children to make homemade pasta. Take time NOW to do this - instill heritage and pride of your food history and culture with your children before it's too late. If we value the passing down of these cultural and family traditions, then fight for the family meal.

In my view, part and parcel of defending the family meal is also a call to defend real communication and community spirit. Aside from voices, no instant communication gadget is allowed at my table. Our ability to communicate through speech is what makes us human. Sitting at a dinner table and encouraging real interactive communication can only improve our capacity to be human.

Eating food is a social and communal event. Perhaps you have concerns as do I that we are losing community and volunteer spirit. I see pockets of youth focused on community and social justice, but it must permeate the generations to follow. I also see that in the world of instant gratification, some have lost the ability and interest to care for our neighbours, whether they be friends or strangers. Have we become so focused on our own needs that we are blind to the needs of others?

I'm a firm believer in random acts of kindness; they bring me instant gratification. What better way to welcome a foreign student, or cheer up someone who's having a lousy day than to bring them a batch of fresh muffins or ask them to share a cup of tea with you in your home. Open your hearts and kitchens to the voice of community and make the world a better place for us all, not just for you.

Perhaps many of you don't know or realize just how instrumental food was in building our nation. Our nation was founded around a dinner table at a dinner table in Charlottetown, PEI. I quote from the PEI Centennial Commission (6):

"Canadian hospitality was so lavish that the delegates were on board eating and drinking until late in the evening... sufficient unity persuaded the gathering to permit the unofficial proclamation of the new nation."

Now, I can't claim to build nations at my dinner table, but for those of you who have gathered there over the years, you know some pretty special stuff happens. Make it happen every day in your home and for those of your clients as well.

\section{Closing food for thought}

As I close, I hope I've left you with food for thought: to know when it's right to be bold, to step out and make a difference. We have one of the most unique and diverse professions that allows for inclusion of diversity in thought and practice and where there's room for each of us to grow in our unique niches and make significant contributions.

I also hope you'll think about when it's time to step back as I did to relish the roots of our profession, to help bring back food into food and nutrition. My firm belief is that food is the tool of my trade and it's what people 'get'. So let's do our job and translate all of our wonderful science into a language that Canadians understand, and that is the language of food.

I also hope we'll all take time to just stand still and breathe - to celebrate our accomplishments, to reflect on our actions, to ensure we are heading toward our vision, to keep the profession vibrant and relevant and to cherish one another.

\section{References}

1. Chuey P, Campbell E, Waisman MS. Dietitians of Canada Simply Great Food: 250 quick, easy and delicious recipes. Toronto: Robert Rose, Inc.; 2007.

2. Waisman MS. Dietitians of Canada Cook! 275 recipes celebrate food from field to table. Toronto: Robert Rose, Inc.; 2011.

3. Waisman MS. Flavour First: delicious food to bring the family back to the table. Regina: Centax Books and Distribution; 2007.

4. Dietitians of Canada. A Vision for Dietitians in 2020: Vision 2020; 2007 [cited 2012 Jun 18]. Available from: http://www.dietitians.ca/Downloadable-Content/ Public/DC_Vision2020_eng.aspx

5. Dietitians of Canada. Healthy Lifestyle - Eating Together Knowledge Pathway. In: Practice-based Evidence in Nutrition [PEN]. Updated 2012 Mar 8 [cited 2012 Jun 18]. Available from: http://www.pennutrition.com/KnowledgePathway.aspx?kpid $=6750$. Access only by subscription.

6. Canada's Smallest Province. A history of Prince Edward Island. In: Bolger FWP, ed. Nation Building at Charlottetown. Charlottetown: The PEI 1973 Centennial Commission; 1973, p.135-155. 